\title{
Prevalence of sleep disorders in children of a public hospital in São Paulo
}

\author{
Clarisse Potasz ${ }^{1}$, Maria Ligia Juliano², Maria José Varela², \\ Patrícia Gouveia Ferraz ${ }^{4}$, Luciane Bizari de Carvalho ${ }^{5}$, \\ Lucila Fernandes do Prado ${ }^{6}$, Gilmar Fernandes do Prado ${ }^{7}$
}

\begin{abstract}
Objective: To investigate the prevalence of sleep disorders in a sample of children from a public hospital in the city of São Paulo, Brazil. Method: 330 children, who came to the clinical laboratory, were consecutively investigated for sleep disorders, using the sleep disturbance scale for children. Gender, age, and social/economical classification were considered. Results: Sleep disordered breathing (SDB) showed higher prevalence in our sample (55\%) than in data found in the literature. Prevalence of sleep hyperhydrosis (SHY) was $27 \%$ considering the whole sample. Boys and children in age range 7.1 to 11 years old showed higher prevalence for SDB as well as children belonging to lower social/economic classifications who were also more prevalent for disorders in the transition of sleepwakefulness. Conclusion: Sleep disorders were highly prevailing in our study, mostly SDB and SHY which were exceedingly more prevalent in boys in relation to international literature.
\end{abstract} Key words: children, sleep disorders.

\section{Prevalência de distúrbios do sono em crianças de um hospital público em São Paulo}

\section{RESUMO}

Objetivo: Investigar a prevalência de distúrbios do sono numa amostra de crianças de um hospital público da cidade de São Paulo, Brasil. Método: 330 crianças que compareceram ao laboratório clínico foram consecutivamente investigadas para a presença de distúrbios do sono, usando-se a Escala de Distúrbios do Sono para crianças. Foram consideradas variáveis como sexo, idade e classificação sócio econômica. Resultados: Os distúrbios respiratórios do sono (DRS) mostraram alta prevalência (55\%) em nossa amostra em relação aos dados encontrados na literatura. A prevalência de hiper hidrose do sono (HHS) foi de 27\%. Meninos e crianças da faixa etária compreendida entre 7,1 e 11 anos apresentaram prevalências mais altas para distúrbios respiratórios do sono assim como crianças pertencentes às classificações sócio econômicas mais baixas, que também foram mais prevalentes para desordens da transição sono-vigília. Conclusão: Os distúrbios do sono foram altamente presentes em nosso estudo, principalmente DRS e HHS, que foram mais prevalentes nos meninos, comparados com a literatura internacional.

Palavras-chave: crianças, distúrbios do sono.

Correspondence Gilmar Fernandes do Prado Rua Cláudio Rossi 394 01547-000 São Paulo SP - Brasil E-mail: gilmarunifesp@yahoo.com.br

Received 7 July 2009

Received in final form 21 September 2009 Accepted 2 October 2009
'Occupational Therapist, Neuro-Sono, Discipline of Internal and Evidence Based Medicine, Discipline of Neurology, Federal University of São Paulo / Children's Hospital Candido Fontoura, São Paulo SP, Brazil; ${ }^{2}$ Dentist, PhD, Neuro-Sono, Discipline of Internal and Evidence Based Medicine, Discipline of Neurology, Federal University of São Paulo, São Paulo SP, Brazil; ${ }^{3}$ Psychologist, Neuro-Sono, Discipline of Internal and Evidence Based Medicine, Discipline of Neurology, Federal University of São Paulo, São Paulo SP, Brazil; ' MD,PhD, Children's Hospital Candido Fontoura, São Paulo SP, Brazil; ${ }^{5}$ Psychologist, PhD, Neuro-Sono, Discipline of Internal and Evidence Based Medicine, Discipline of Neurology, Federal University of São Paulo, São Paulo SP, Brazil; ${ }^{6} \mathrm{MD}, \mathrm{PhD}$, Neuro-Sono, Discipline of Internal and Evidence Based Medicine, Discipline of Neurology, Federal University of São Paulo, São Paulo SP, Brazil; ${ }^{7}$ MD,PhD, Neuro-Sono, Discipline of Internal and Evidence Based Medicine, Discipline of Neurology, Federal University of São Paulo, São Paulo SP, Brazil. 
Sleep includes physiological and behavioral aspects that can be measured with the use of interviews, questionnaires, or with video polysomnographic technology ${ }^{1}$. It has an important role in children's development, influencing not only physical and emotional maturation, but also the cognitive function ${ }^{2}$.

Sleep disorders (SD) are not a rare phenomenon. Patterns and arising of sleep problems are influenced in pediatric populations by social, cultural and familiar models, as well as biological and psychological factors. Therefore all of these aspects must be considered when examining sleep behaviors ${ }^{1}$. Prevalence of SD in childhood varies around $19 \%$ to $30 \%{ }^{1}$. Data are controversial mainly due to methodological differences among studies, with values for SD diverging between 1 to $43 \%$ in the international literature ${ }^{2,3}$. SD varies with age, stage of development, and ethnicity ${ }^{1,2}$. However, the consequences of SD seem to be universal, reflecting in the children's diurnal behavior as excessive daytime sleepiness (EDS), and mood changes ${ }^{4}$. The regulation of mood and modulation of emotions seem also to be affected by quantity and quality of sleep ${ }^{1,3}$. Superior levels of cognitive function like the capacity of abstraction, flexibility, and creative thinking appear to be sensible to the effects of SD or insufficient sleep ${ }^{2,5}$. EDS a quite common factor in school environments, may appear due to sub optimal duration of nocturnal sleep, besides the SD, leading to a poor academic performance and attention difficulties ${ }^{2,6}$.

The concept that the relationship between sleep and a child's well being is bi-directional seems clear enough. These factors per se would justify the realization of studies focusing the prevalence of SD in infancy. However, data in the literature are scarce and poorly standardized. This problem is more common in certain SD like sleep hyperhydrosis (SHY) which seems to be associated to the presence of sleep disordered breathing (SDB). There are no studies in the international literature that have evaluated specifically the prevalence of SHY.

The objective of this study was to evaluate the prevalence of SD in a pediatric population of a public hospital in the city of São Paulo, Brazil, in relation to gender, age, and social economic status, using a validated tool.

\section{METHOD}

\section{Population and setting}

We studied 330 children (166 boys, mean age $8.9 \pm 3$ years old), recruited at Candido Fontoura Children's Hospital $(\mathrm{CFCH})$, a pediatric facility of the public health system, in the city of São Paulo, from February to December, 2005.

Children and caregivers participating in the study came spontaneously to the clinical laboratory of the hospital for the realization of blood tests. Children's inclusion was sequential for all of those who came to the lab for the realization of exams that included blood tests.
The children should be accompanied by caregivers capable of answering the questionnaires used in the study. Those children that came to the laboratory in order to have tests that did not involve blood drawings, those with psychiatric and neurological disorders, and those who came for tests related to contagious diseases were excluded.

The present study was authorized by both ethics board (CFCH: process number 13000736; Federal University of São Paulo: process 1679/05). All the children's caregivers signed a consent form.

\section{Questionnaires}

All caregivers filled in charts with the child's data. Trained researchers used two questionnaires to identify sleep and social economic variables. Social-economic parameters were assessed using the Escala Social de Pelotas ${ }^{7}$, which classifies the population in six categories according to profession and educational levels. Its scores range from 1 (the highest) to 6 (the lowest). The group we studied presented 5 children that lived in institutions; they were classified socially as 0 . Sleep variables were assessed through the sleep disturbance scale for children $(\mathrm{SDSC})^{8}$, recently validated in Brazil ${ }^{9}$, comprising of 26 questions and stratified answers in a Likert scale, according to frequency.

\section{SD considered in the study according to the sleep disturbance scale for children ${ }^{8}$ \\ Disorders of initiating and maintaining sleep (DIMS):}

These disorders refer to those problems appearing at sleep time as well as frequent arousals during the night. They are highly prevalent in children, and can be found in approximately $30 \%$ of infants and pre-scholars. The refusals to go to bed, plus other typical behaviors at sleep time (verbal protests, crying, etc) are clinically considered as behavioral insomnia of childhood. Night arousals are considered when caregivers regard them as problematic, usually because they are frequent and/or prolonged, requiring some kind of intervention ${ }^{10}$.

Sleep disordered breathing (SDB): Pediatric sleep apnea and hypopnea syndrome (OSAS) is characterized by partial upper airway obstructions, intermittent complete or partial obstruction, or both prolonged and intermittent obstruction that disrupts ventilation during sleep, with the maintenance of respiratory effort ${ }^{2}$. In children it is followed by hypercapnia and arterial oxygen desaturation. An important symptom is snoring, which is present in practically all children showing OSAS. The intensity of snoring is not related to the severity of the syndrome. Prevalence in the literature varies from $2 \%$ to $3 \%{ }^{10}$.

Disorders of arousal (DA): Consist of confusional arousals represented by mental or behavioral stunning during or right after awakening. They are more common 
during those arousals from slow-wave sleep in the first part of the night. The individual appears to be disoriented in relation to time and space, and may show a slowness of speech. Prevalence in children between 3 and 13 years old is $17.3 \%$, with no differences between genders ${ }^{10}$.

Disorders in the transition of sleep-wakefulness (DTSW): Nightmare disorders: the child presents with recurrent nightmares including disturbing mental experiences. This disorder occurs generally in the rapid eye movement (REM) stage and usually leads to arousals. Its prevalence is 5 to $10 \%$ in children between 3 to 5 years of age ${ }^{10}$. Sleep terrors are arousals from slow-wave sleep, followed by a cry or loud scream. Behavioral manifestations may also appear as well as manifestations of the autonomic nervous system, reflecting intense fear. Frequently, there are strong autonomic discharges like tachycardia, tachypnea, flushing of the skin, diaphoresis, mydriasis, and increased muscle tone ${ }^{10}$. Also in this group, sleep related bruxism is an oral activity characterized by tooth-grinding sounds or tooth clenching during sleep frequently associated to arousals. It may cause abnormal wear of the teeth and its etiology is still uncertain. The highest prevalence is during childhood, around 14 to $17 \%$, and decreases with age $\mathrm{e}^{10}$. In sleep talking as the name states, the individual produces words and speech while sleeping with different levels of inteligibility ${ }^{10}$. It is a very common SD in the general population and may have a genetic component. It is highly prevalent, and is reported in half of the children in general with no differences between genders ${ }^{10}$. Head banging or body rocking is a rhythmic movement disorder related to sleep, characterized by repetitive, stereotyped, rhythmic motor behaviors (which are not tremors). This disorder occurs during drowsiness or sleep, and involves large muscle groups. Its prevalence is $59 \%$ in children at 9 months of age, and 5\% in children around 5 years of age, with no differences between genders ${ }^{10}$.

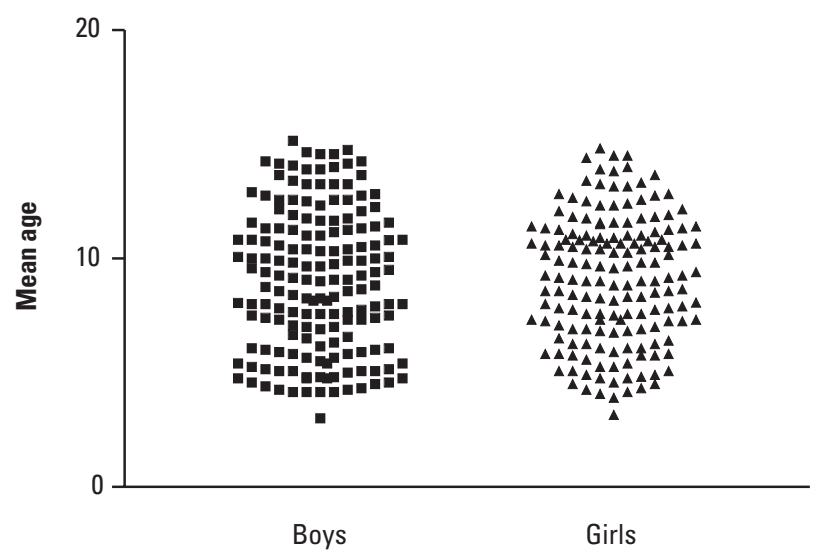

Fig 1. Distribution of the 330 children according to age and gender.
Excessive daytime sleepiness (EDS) is defined in childhood as a larger amount of sleep than in other children of the same age. The child has a greater necessity of naps than his/her companions of the same age, or shows a change in sleep patterns with an increase of sleeping hours ${ }^{11}$.

Sleep hyperhydrosis (SHY): This disorder consists of night sweats; there are no data in the literature about the prevalence of this sleep disorder.

\section{Sample stratification}

The sample was divided in three subgroups according to age range, following developmental criteria: age range 1 , (from 4 to 7 years); range 2, (7.1 to 11 years); range 3 , (11.1 to 14 years).

\section{Data analysis}

Data were compared using Prism 3.0 and SPSS 13.0 software for statistical analyses. We used Student T test for comparison of continuous data, chi square and exact Fisher test for categorical comparisons, taking in account gender, age range, and social classification ${ }^{7}$. Data are presented in means and standard deviation.

\section{RESULTS}

Three hundred and thirty children participated in the study, 166 boys $(50.45 \%$, mean age $=8.9 \pm 3.0)$ and 164 girls (49.54\%, mean age $=9.0 \pm 2.77)$. There were no differences in age by gender distribution ( $\mathrm{p}=0.76$, Fig 1$)$.

\section{Prevalence of SD by gender and age range}

There was no difference in the general distribution of $\mathrm{SD}$ in relation to gender $(\mathrm{p}=0.48)$ or age $(\mathrm{p}=0.38)$, when the whole sample was considered (Table 1).

When we studied the groups from age ranges 2 and 3 (Fig 2), the number of children with SD was 67 (19.36\%) in age range 2 and $27(8.51 \%)$ in age range $3(p=0.03$; $\mathrm{CI}=1.07-3.34)$. SDB was more prevalent in age range 2 $(p=0.05)$. The prevalence of SHY was significantly higher in age range 1 than $3(n=25,7 \% ; n=10,3 \%$ respectively. $\mathrm{p}=0.009$ and $\mathrm{CI}=1.27-7.29)$. The other SD did not show significant differences in relation to age (Table 2).

When we analyzed SD in relation to gender, we observed a higher prevalence of SHY in boys $(n=40,12 \%)$ than in girls $(\mathrm{n}=22,6 \%) ; \mathrm{p}=0.002$ and $\mathrm{CI}=1.06=3.56$. Prevalence of SD according to gender are shown in Fig 3. There were no differences in the distribution of the other $\mathrm{SD}$ in relation to gender.

\section{SD distribution according to social-economic level}

Most of the children in our study belonged to levels 4 (36\%) and level 6 (36\%). Table 3 shows the distribution of the sample in different social-economic levels in relation to SD. There were no representatives in levels 1 and 2 . 
Table 1. Prevalence of sleep disorders in the sample, in relation to gender and age.

\begin{tabular}{|c|c|c|c|c|c|c|c|}
\hline & \multicolumn{2}{|c|}{ Total sample } & \multicolumn{2}{|c|}{ Boys } & \multicolumn{2}{|c|}{ Girls } & \multirow[b]{2}{*}{$p$} \\
\hline & N (\%) & age & N (\%) & age & N (\%) & age & \\
\hline DIMS & $7(2.1)$ & $11.3 \pm 2.8$ & $4(1.2)$ & $12.5 \pm 2.7$ & $3(0.9)$ & $9.6 \pm 2.3$ & 0.98 \\
\hline SDB & 127 (38.6) & $8.9 \pm 2,6$ & $70(21.2)$ & $8.7 \pm 2.6$ & $57(17.4)$ & $8.7 \pm 2.8$ & 0.24 \\
\hline$A D$ & $8(2.4)$ & $8.9 \pm 2.4$ & $2(0.6)$ & $11.5 \pm 1.5$ & $6(1.8)$ & $7.9 \pm 1.9$ & 0.17 \\
\hline DTSW & $5(1.5)$ & $9.4 \pm 3.8$ & $4(1.2)$ & $8.4 \pm 4.2$ & $1(0.3)$ & 11.9 & 0.37 \\
\hline EDS & $22(6.7)$ & $9.3 \pm 2.9$ & $11(3.3)$ & $9.7 \pm 3.0$ & $11(3.3)$ & $8.9 \pm 2.9$ & 0.84 \\
\hline SHY & $62(18.8)$ & $8.2 \pm 2.8$ & $40(12.2)$ & $8.3 \pm 2.8$ & $23(6.9)$ & $7.9 \pm 2.5$ & 0.028 \\
\hline
\end{tabular}

Age is given in years. DIMS: disorders of initiating and maintaining sleep; SDB: sleep disordered breathing; AD: arousal disorders; DTSW: disorders in the transition of sleep-wakefulness; EDS: excessive daytime sleepiness; SHY: sleep hyperhydrosis,

Table 2. Distribution of sleep disorders in relation to age.

\begin{tabular}{lcccc}
\hline & $\begin{array}{c}\text { Age range 1 } \\
\text { N (\%) }\end{array}$ & $\begin{array}{c}\text { Age range 2 } \\
\text { N (\%) }\end{array}$ & $\begin{array}{c}\text { Age range 3 } \\
\text { N (\%) }\end{array}$ & p \\
\hline With DIMS & 0 & $3(0.9)$ & $4(1.2)$ & 0.11 \\
No DIMS & $92(27.8)$ & $144(43.6)$ & $87(26.3)$ & \\
With SDB & $33(10)$ & $67(20.3)$ & $28(8.4)$ & 0.03 \\
No SDB & $59(17.8)$ & $80(24.2)$ & $63(19)$ & \\
With AD & $2(0.6)$ & $5(1.5)$ & $1(0.3)$ & 0.52 \\
No AD & $90(27.2)$ & $142(43)$ & $90(27.2)$ & \\
With DTSW & $1(0.3)$ & $1(0.3)$ & $3(0.9)$ & 0.25 \\
No DTSW & $91(27.5)$ & $146(44.2)$ & $88(26.6)$ & \\
With EDS & $6(1.8)$ & $11(3.3)$ & $5(1.5)$ & 0.83 \\
No EDS & $86(26)$ & $136(41.2)$ & $86(26)$ & \\
With SHY & $25(7.5)$ & $28(8.4)$ & $10(3)$ & 0.009 \\
No SHY & $67(20.3)$ & $119(36)$ & $81(24.5)$ & \\
\hline
\end{tabular}

DIMS: disorders of initiating and maintaining sleep; SDB: sleep disordered breathing; AD: arousal disorders; DTSW: disorders in the transition of sleepwakefulness; EDS: excessive daytime sleepiness; SHY: sleep hyperhydrosis. Age range 1: 4 to 7 years old; age range 2:7.1 to 11 years old; age range 3: 11.1 to 14 years old.

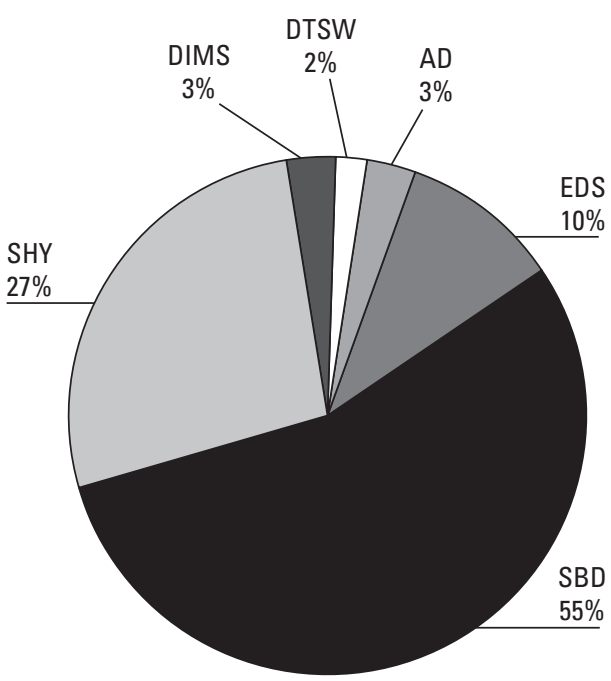

Fig 2. Distribution of sleep disorders in the whole sample. DTSW: disorders in the transition of sleep-wakefulness; DIMS: disorders of initiating and maintaining sleep; SHY: sleep hyperhydrosis; SDB: sleep disordered breathing; EDS: excessive daytime sleepiness; AD: arousal disorders.

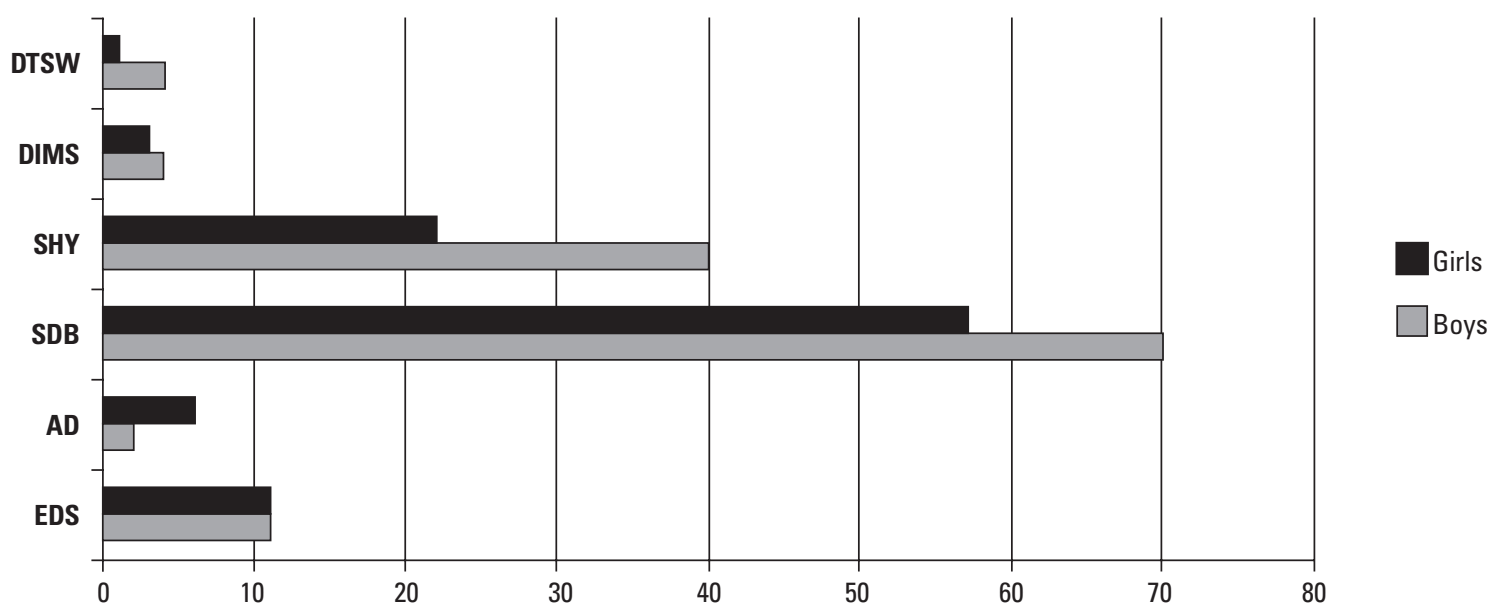

Fig 3. Distribution of sleep disorders in the sample regarding gender. DTSW: disorders in the transition of sleep-wakefulness; DIMS: disorders of initiating and maintaining sleep; SHY: sleep hyperhydrosis; SDB: sleep disordered breathing; AD : arousal disorders; EDS: excessive daytime sleepiness. 
Table 3. Distribution of sleep disorders in relation to social/economic classification.

\begin{tabular}{|c|c|c|c|c|c|c|c|c|c|c|c|c|}
\hline & \multicolumn{2}{|c|}{ Group 0} & \multicolumn{2}{|c|}{ Group 2} & \multicolumn{2}{|c|}{ Group 3} & \multicolumn{2}{|c|}{ Group 4} & \multicolumn{2}{|c|}{ Group 5} & \multicolumn{2}{|c|}{ Group 6} \\
\hline & $\mathrm{n}$ & $\%$ & $\mathrm{n}$ & $\%$ & $\mathrm{n}$ & $\%$ & $n$ & $\%$ & $\mathrm{n}$ & $\%$ & $n$ & $\%$ \\
\hline DIMS & 0 & - & 0 & - & 0 & - & 0 & - & 2 & 0.6 & 3 & 0.9 \\
\hline SDB & 2 & 0.6 & 0 & - & 12 & 3.6 & 0 & - & 53 & 16.1 & 37 & 11.2 \\
\hline$A D$ & 0 & - & 1 & 0.3 & 0 & - & 2 & 0.6 & 1 & 0.3 & 4 & 1.2 \\
\hline DTSW & 0 & - & 1 & 0.3 & 0 & - & 2 & 0.6 & 1 & 0.3 & 1 & 0.3 \\
\hline EDS & 0 & - & 1 & 0.3 & 3 & 0.9 & 6 & 1.8 & 1 & 0.3 & 11 & 3.3 \\
\hline SHY & 0 & - & 0 & - & 3 & 0.9 & 23 & 6.9 & 16 & 4.8 & 20 & 6 \\
\hline
\end{tabular}

Group 0: institutionalized children; Group 3: highest classification in this sample; class 6 is the lowest classification. DIMS: disorders of initiating and maintaining sleep; SDB: sleep disordered breathing; AD: arousal disorders; DTSW: disorders in the transition of sleep-wakefulness; EDS: excessive daytime sleepiness; SHY: sleep hyperhydrosis.

The distribution of SD among the social-economic levels showed a higher prevalence of SDB in group 5 $(\mathrm{n}=53 ; 16 \%)$ and $6(\mathrm{n}=37 ; 11.2 \%)$. Group $4(\mathrm{n}=2 ; 6 \%), 5$ $(\mathrm{n}=53 ; 16 \%)$ and $6(\mathrm{n}=37 ; 11 \%)$ showed higher prevalence of DTSW than group $2(0 \%), \mathrm{p}<0.05$.

Groups $4(\mathrm{n}=6 ; 1.8 \%), 5(\mathrm{n}=1 ; 0.3 \%)$ and $6(\mathrm{n}=11$; $3.36 \%$ ) showed a higher prevalence of EDS when compared to groups $3(n=3 ; 0.9 \%)$ and $2(n=1 ; 0.3 \%), p<0.05$.

Children in group $6(\mathrm{n}=20 ; 6 \%)$ of the social-economic classification showed a higher prevalence of SHY than group $5(\mathrm{n}=16 ; 4.8 \%), \mathrm{p}<0.05$. Children in levels 5 and 6 presented higher prevalence of SHY than those from groups $4(n=23 ; 6,9 \%)$ and $3(n=3 ; 0.9 \%), p<0.05$. There were no differences in the distribution of other SD in relation to social-economic level.

\section{DISCUSSION}

The aim of our study was to investigate the prevalence of SD in a sample of Brazilian children living in the city of São Paulo, who went to a public pediatric hospital for blood tests. We investigated the presence of these disorders in relation to age range, gender and social-economic level, using Bruni's scale criteria ${ }^{8}$.

The first point that comes to our attention is the higher prevalence of SDB in our sample when compared to data in the literature; our children showed a prevalence of $55 \%$ for this SD, while international data fluctuate around $2-3 \%^{2,3,10}$.

This discrepancy among data may be the consequence of the methodology used to detect the disorder. In our study, information was obtained through the caregiver's answers to a specific questionnaire ${ }^{10}$ translated and validated in Portuguese ${ }^{9}$. The referred questionnaire is consonant with the categories used by the Centers of the American Society of Sleep Disorders ${ }^{10}$, which recommended a more adequate classification for pediatric SD. This questionnaire takes in account snoring and other symptoms indicating respiratory problems in the SDB category. The assessment of SDB in children has been based on caregiv- er's reports, for clinical and research purposes, as a risk indicator for OSAS ${ }^{12}$. These reports may be considered as predictors of pediatric OSAS.

A large number of published studies used adult criteria to detect $\mathrm{SDB}^{13}$. None of them took in account for example, the presence of upper airway resistance syndrome in their evaluations. The diagnosis of this problem would require esophageal pressure monitoring, a non-routine proceeding in the majority of sleep centers ${ }^{14}$.

A study about SD, using an epidemiological survey questionnaire from the Sleep Center in the Children's Hospital and Sydney University in Australia, that was adapted, translated into Chinese, and revised for regional dialects, examined children belonging to age range 2 to 12 years, divides SDB in frequent snoring (5.6\%), oral breathing $(4.1 \%)$, choking $(0.9 \%)$, and respiratory pauses $(0.2 \%)^{15}$.

Other studies, employing polygraphic and clinical evaluations, report differences in the prevalence of habitual snoring from country to country, with numbers between $6 \%$ and $26 \%{ }^{16}$. One of these investigations studied Australian children between 2 and 5 years of age, using a questionnaire developed by the researchers in cooperation with specialists in SDB, but not yet validated. This study reported a prevalence of $10.5 \%$ for $\mathrm{SDB}^{17}$. Some studies conducted in Italy (parental reports and ambulatory monitoring) and Thailand (postal questionnaires about snoring and other symptoms of SDB), described habitual snoring varying from $4.9 \%$ to $34.5 \%$ in elementary school children ${ }^{18,19}$.

The majority of studies published in the international literature about pediatric OSAS agree that this is a common SD, but considerably sub diagnosed in this population $^{2-4,20,21}$.

In our study, children may be more affected by allergic and/or respiratory diseases, which favor the presence of SDB. The exposure to high levels of environmental pollution which characterizes an urban center like São Paulo might be an explanation for this finding. There are data in the literature about a higher prevalence for snoring, oral 
breathing and periodic limb movement in sleep in urban areas $^{15}$. A study ${ }^{22}$ shows prevalence for habitual snoring of $15.2 \%$. Participants included in this research showed high numbers for asthma (18.7\%), and allergies (44\% for allergic rhinitis and hay fever). Allergies are a risk factor for $\mathrm{SDB}^{23}$, as well as increases in tonsils and/or adenoids among other causes for obstruction ${ }^{23,24}$.

The well known problems in the Brazilian health system may be hampering the diagnosis of tonsil hypertrophy in children who snore or present OSAS, or even delaying necessary surgeries for the resolution or improvement of such disease ${ }^{25}$.

Our data showed a significant difference in the prevalence of SDB and SHY in relation to age range. SDB presented difference in prevalence between age range 2 (7.1 to 11 years old) with $67(19.3 \%)$ children, and age range 3 (11.1 to 14 years old) with 27 (8.48\%) children. These data agree with a study performed in the United States (Division of Pediatric Otolaryngology, State University of New York Downstate), in $2004^{14}$, on the evaluation of pediatric OSAS. In this study there was a higher prevalence of OSAS diagnosed through polisomnography in children around 7 years of age.

In pediatric populations, the most common cause for SDB (and OSAS) is tonsilar hypertrophy, mainly in preschool years, when there is an accentuated growing of lymphoid tissue ${ }^{21}$. This fact, added to the referred problems for diagnosis and treatment of the disease may explain the higher prevalence of OSAS in age range 2 .

SHY showed difference in prevalence between age range $1(7.5 \%)$ and age range $3(3 \%)$. Nocturnal sweating is not much studied in the literature, but some studies already relate this disorder with $\mathrm{SDB}^{8}$. In the age range we studied (childhood and adolescence), SD not always are an isolated event. Frequently there may be an overlap of signs and symptoms in the same person ${ }^{8}$.

Night sweating seems to be a common symptom of $\mathrm{OSAS}^{26}$, but the pathogenical mechanisms are not clear yet. This relationship may be due to an increase in the respiratory effort linked to the mechanical obstruction, or to an indirect effect of sympathetic activation of the vasopressin systems ${ }^{27}$. Considering SDB and SHY as problems that seem to move together, the higher prevalence in younger ages as compared to older ones seems logical.

Boys presented higher prevalence of SHY. Literature shows a higher prevalence of SD in males ${ }^{15}$ mainly $\mathrm{SDB}^{15,21,22}$, agreeing with data found in our study. We did not find epidemiological reports on SHY, but if we consider that this disorder may be associated to SDB, the higher prevalence in boys concurs with international literature ${ }^{16,21,22}$.

Regarding the social classification of the sample, we found significant differences in prevalences of some SD in some social/economic groups. Literature is very poor on papers that analyze social factors and SD in children. There seems to be a relationship between SD and the number of people living in the house (the bigger the number of inhabitants, the higher the chance of the presence of SD in resident children $)^{28}$.

Parents' behavior at sleep time also influences sleep latency (longer for a more accentuated parents' presence), higher incidence of nocturnal arousals, and a reduction in total sleep time ${ }^{29}$. Cultural factors are important determinants of sleep practices and behaviors in children; these factors may influence the type and frequency of SD in pediatric populations ${ }^{1}$.

Sleep disorders in childhood are also associated to the level of parents' knowledge about sleep hygiene ${ }^{30}$. A study found in the literature ${ }^{31}$, related active as well as passive exposition to television, as a facilitating factor for the appearance of SD. This same study showed that the type of programming to which that child is exposed, also influences his/her patterns of sleep. The exposure to adult contents was highly correlated to the occurrence of SD.

The population in our study belongs in its majority to lower economic/social groups. This might explain the difference for some SD. This particular group of people might live in smaller houses, where super population and inadequate sleep environment, mainly regarding noise and ventilation, favored the presence of SD. In the same way, the fact that parents might be sharing the same room or even the same bed with their children, might facilitate their perception about SD in these children.

Small surroundings also propitiate a constant exposition to television, even at sleep time, a factor that may be worsened by the lack of knowledge about good sleep hygiene.

In conclusion, SD were highly prevalent in our study, mostly SDB and SHY which were exceedingly more prevalent in boys. It also demonstrated a higher prevalence of other SD in the group we studied in relation to international literature. The variables that account for these numbers need to be studied in our pediatric population, so that public health politics may be adopted regarding prevention and treatment of SD.

ACKNOWLEDGMENTS - The authors would like to thank the board of Candido Fontoura Children's Hospital and the therapists of the neuropsychiatry service for their collaboration to the realization of this study.

\section{REFERENCES}

1. Owens JA. Sleep in children: cross-cultural perspectives. Sleep Biol Rhyt 2004;2:165-173.

2. Carvalho LBC, Prado LBF, Silva L, et al. Cognitive dysfunction in children with sleep-disordered breathing. J Child Neurol 2005;20:400-404.

3. Medeiros M, Carvalho LBC, Silva TA, Prado LBF, Prado GF. Sleep disorders are associated with impulsivity in school children aged 8 to 10 years. Arq Neuropsiquiatr 2005;63:761-765. 
4. Fredriksen K, Rhodes J, Reddy R, Way N. Sleepless in Chicago: tracking the effects of adolescent sleep loss during the middle school years. Child Dev 2004;75:84- 95.

5. Moran CA, Carvalho LBC, Prado LBF, Prado GF. Sleep disorders and starting time to school impair balance in 5-year-old children. Arq Neuropsiquiatr 2005;63:571-576.

6. Wolfson AR, Carkskadon MA. Understanding adolescents' sleep patterns and school performance: a critical appraisal. Sleep Med Rev 2003;7:491-506.

7. Lombardi C, Bronfman M, Facchini LA, et al. Operacionalização do conceito de classe social em estudos epidemiológicos. Rev Saúde Publ 1988;22:253-265.

8. Bruni O, Salvatori O, Guidetti V, et al. The sleep disturbance scale for children (SDSC). Construction and validation of an instrument to evaluate sleep disturbances in childhood and adolescence. J Sleep Res 1996;5:251-261.

9. Ferreira VR, Carvalho LBC, Ruotolo F, Morais JF, Prado LBF, Prado GF. Sleep disturbance scale for children: translation, cultural adaptation, and validation. Sleep Med 2009;10:457-463.

10. The International Classification of Sleep Disorders. American Academy of Sleep Medicine. Westchester: AASM, 2005.

11. Guilleminault C, Korokobin R, Winkle R. A review of 50 children with obstructive sleep apnea syndrome. Lung 1981;159:275-287.

12. Montgomery-Downs HE, O'Brien L, Holbrook CR, Gozal D. Snoring and sleepdisordered breathing in young children: subjective and objective correlates. Sleep 2004;27:87-94.

13. Spruyt K, O'Brien LM, Coxon APM, Cluydts R, Verleye G, Ferri R. Multidimensional scaling of pediatric sleep breathing problems and bio-behavioral correlates. Sleep Med 2006;7:269-280.

14. Goldstein NA, Pugazhendhi V, Rao SM, et al. Clinical assessment of pediatric obstructive sleep apnea. Pediatrics 2004;114:33-43.

15. Liu X, Ma Y, Wang Y, et al. Brief report: an epidemiologic survey of the prevalence of sleep disorders among children 2 to 12 years old in Beijing, China. Pediatr 2005;115:266-268.

16. Gastaut H, Broughton RA. A clinical and polygraphic study of episodic phenomena during sleep. Recent Adv Biol Psychiatr 1965:197-221.

17. Lu LR, Peat JK, Sullivan CE. Snoring in preschool children: prevalence and association with nocturnal cough and asthma. Chest 2003;124:587-593.
18. Castronovo V, Zucconi M, Nosetti L, et al. Prevalence of habitual snoring and sleep-disordered breathing in preschool-aged children in an Italian community. J Pediatr 2003;142:377-382.

19. Brunetti L, Rana S, Lospalluti ML, et al. Prevalence of obstructive sleep apnea syndrome in a cohort of 1,207 children of southern Italy. Chest 2001;120: 1930-1935.

20. Marcus CL, Fernandes LF, Lutz J, et al. Developmental changes in upper airway dynamics. J Appl Physiol 2004;97:98-108.

21. Ramos RTT, Daltro CHC, Gregorio PB, et al. SAHOS em crianças: perfil clínico e respiratório polissonográfico. Rev Bras Otorrinolaringol 2006;72:355-361.

22. Zhang G, Spickett J, Rumchev K, Lee AH, Stick S. Snoring in primary school children and domestic environment: a Perth school based study. Resp Res 2004;5:19-24.

23. Camhi SL, Morgan WJ, Pernisco N, Quan SF. Factors affecting sleep disturbances in children and adolescents. Sleep Med 2000;1:117-123.

24. Aittokallio T, Gyllenberg M, Polo O. A model of a snorer's upper airway. Math Biosci 2001;170:79-90.

25. Antunes ML, Frazatto R, Macoto EK, Vieira FM, Yonamine FK. Mutirão de cirurgias de adenotonsilectomias: uma solução viável? Rev Bras Otorrinolaringol 2007;73:446-451.

26. Carotenuto M, Bruni O, Santoro N, et al. Waist circumference predicts the occurrence of sleep-disordered breathing obese children and adolescents: a questionnaire-based study. Sleep Med 2006;7:357-361.

27. Woodson BT, Brusky LT, Saraujen A, Jaradeh S. Association of autonomic dysfunction and mild obstructive sleep apnea. Otorryngol Head Neck Sur 2004;130:643-648.

28. Liu X, Sun Z, Uchiyama M, Shibui K, Kim K, Okawa M. Prevalence and correlates of sleep problems in Chinese schoolchildren. Sleep 2000;23:1053-1062.

29. Giannotti F, Cortesi $\mathrm{f}$, Sebastiani T, Vagnoni C. Sleeping habits in Italian children and adolescents. Sleep Biol Rhyt 2005;3:15-21.

30. Potasz C, Carvalho LBC, Natale VB, et al. Sleep disorders and children behavior. Rev Neuroci 2008;16:124-129.

31. Paavonen EJ, Pennonen M, Roine M, Valkonen S, Hikainen AR. TV exposure associated with sleep disturbances in 5- to 6-year-old children. J Sleep Res 2006;15:154-161. 